\title{
All-optical OFDM system using a wavelength selective switch based transmitter and a spectral magnification based receiver
}

\section{Guan, Pengyu; Lefrancois, S.; Lillieholm, Mads; Mulvad, Hans Christian Hansen; Røge, Kasper Meldgaard; Hu, Hao; Schroeder, J.; Eggleton, B. J.; Geng, Z.; Lowery, A. J.}

Total number of authors:

12

Published in:

Proceedings of 2014 European Conference on Optical Communication

Link to article, DOI:

10.1109/ECOC.2014.6964089

Publication date:

2014

Document Version

Peer reviewed version

Link back to DTU Orbit

Citation (APA):

Guan, P., Lefrancois, S., Lillieholm, M., Mulvad, H. C. H., Røge, K. M., Hu, H., Schroeder, J., Eggleton, B. J., Geng, Z., Lowery, A. J., Morioka, T., \& Oxenløwe, L. K. (2014). All-optical OFDM system using a wavelength selective switch based transmitter and a spectral magnification based receiver. In Proceedings of 2014 European Conference on Optical Communication (pp. 1-3). IEEE. https://doi.org/10.1109/ECOC.2014.6964089

\section{General rights}

Copyright and moral rights for the publications made accessible in the public portal are retained by the authors and/or other copyright owners and it is a condition of accessing publications that users recognise and abide by the legal requirements associated with these rights.

- Users may download and print one copy of any publication from the public portal for the purpose of private study or research.

- You may not further distribute the material or use it for any profit-making activity or commercial gain

- You may freely distribute the URL identifying the publication in the public portal 


\section{All-optical OFDM System using a Wavelength Selective Switch based Transmitter and a Spectral Magnification based Receiver}

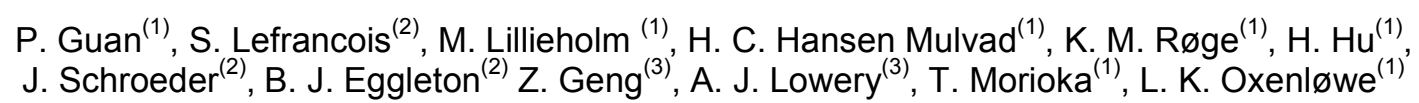

(1) DTU Fotonik, Department of Photonics Engineering, Technical University of Denmark, Ørsteds Plads, Building 343, DK-2800 Kgs. Lyngby, Denmark, pengu@fotonik.dtu.dk

(2) Centre for Ultrahigh bandwidth Devices for Optical Systems (CUDOS), School of Physics, The University of Sydney, NSW 2006, Australia

(3) CUDOS, Department of Electrical and Computer Systems Engineering, Monash University, Clayton, VIC 3800 , Australia

Abstract We demonstrate an AO-OFDM system with a WSS-based transmitter and time-lens based receiver for spectral magnification, achieving BER $10^{-9}$ for a $28 \times 10$ Gbit/s DPSK AO-OFDM signal. Furthermore, the receiver performance for DPSK and DQPSK is investigated using Monte Carlo simulations.

\section{Introduction}

All-optical OFDM (AO-OFDM) systems are based on OFDM subcarrier multiplexing and demultiplexing in the optical domain, and have enabled high spectral-efficiency OFDM superchannels with Tbit/s capacity ${ }^{1,2}$. An AO-OFDM transmitter can be implemented by optical discrete Fourier transformation (ODFT) based on cascaded delay interferometers ${ }^{1}$, arrayed waveguide grating routers $^{3}$, wavelength selective switches (WSS), or by time-domain optical Fourier transformation (OFT) based on time lenses ${ }^{4}$. The WSS-based ODFT has the advantage of reconfigurable OFDM generation, which greatly increases the system flexibility ${ }^{3}$. For the AO-OFDM receiver, most demultiplexing methods require a sampling gate for each subcarrier to avoid detrimental inter-carrierinterference $(\mathrm{ICI})^{1}$. Recently, we proposed OFDM demultiplexing by spectral magnification followed by optical band-pass filtering (OBPF) $)^{5}$. The spectral magnification leads to reduced $\mathrm{ICl}$ after filtering, thus allowing for direct detection of all subcarriers without using sampling gates. The scheme is demonstrated for a $10 \times 10$ Gbit/s DPSK OFDM signal, but the system was based on even and odd subcarriers which underestimates the influence of $\mathrm{ICl}$.

In this paper, we report a $28 \times 10 \mathrm{Gbit} / \mathrm{s}$ DPSK
AO-OFDM system using a WSS based transmitter, employing four independent ports for the subcarrier multiplexing, followed by a spectral magnification based receiver. At the receiver, we use four-wave mixing (FWM) based time-lenses and demonstrate $4 \mathrm{x}$ spectral magnification of the OFDM super-channel, thus achieving a $B E R<10^{-9}$ for nearly all subcarriers after OBPF. In addition, Monte Carlo simulations predicts the scheme will also work for DQPSK.

\section{Principle}

The principle of our AO-OFDM system is shown in Fig. 1. At the transmitter, the output of a mode locked laser (MLL) with repetition rate $f_{\mathrm{R}}$ is split in $\mathrm{N}$ paths. Each path is data modulated at $f_{R}$, converting the discrete comb-lines into a continuous white spectrum. AO-OFDM is then generated by ODFT using a WSS ${ }^{2}$, where each subcarrier is obtained by individually sincshaping the input white spectrum with the desired subcarrier spacing $f_{\mathrm{S}}$, and the full OFDM super-channel is then obtained by passively combining all subcarriers together. In the receiver, a combination of time-lenses is employed for spectral magnification ${ }^{5}$. Timelenses are based on quadratic phase modulation and dispersion. Time-lens 1 converts the OFDM spectrum to a Nyquist-OTDM signal (frequency-to-time conversion), and time-lens 2

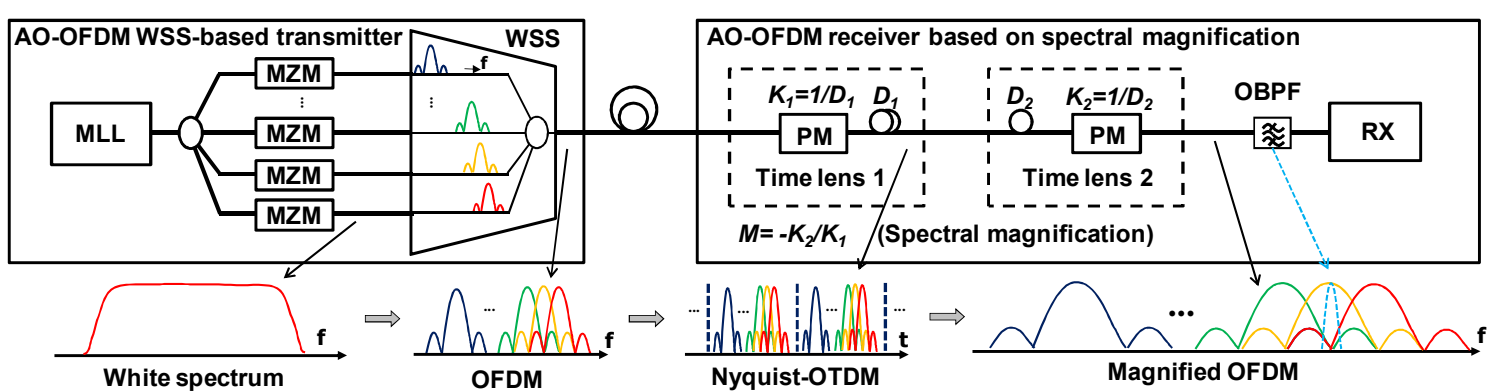

Fig. 1: Principle of the AO-OFDM transmission system 


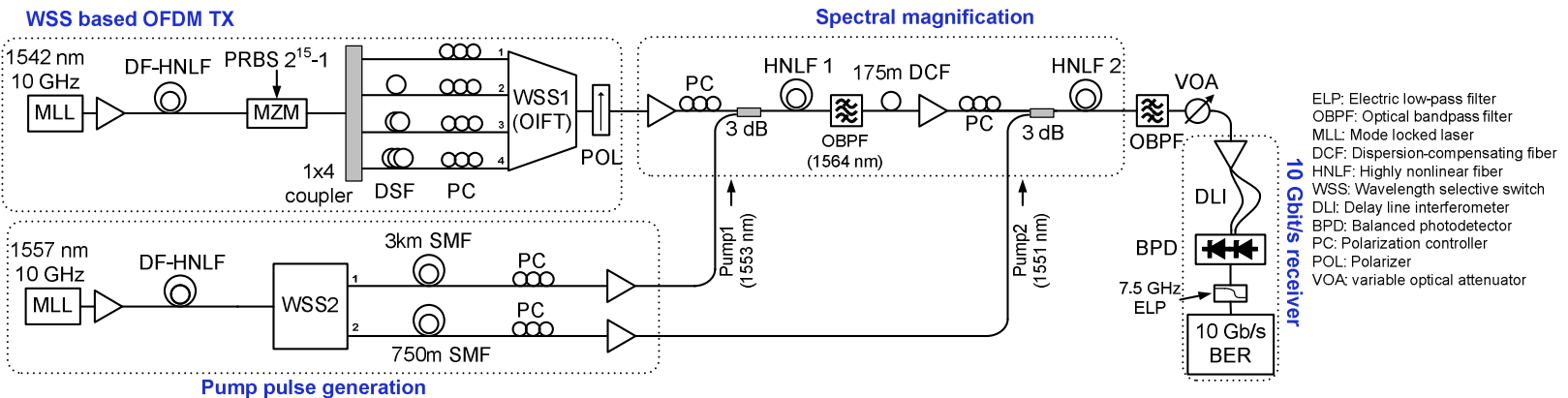

Fig. 2: Experimental setup of $28 \times 10 \mathrm{Gbit} / \mathrm{s}$ DPSK AO-OFDM system using a WSS and spectral magnification

converts it back to the spectral domain (time-tofrequency conversion). The magnification factor $M$ is determined by the ratio of the two employed chirp rates. The magnified spectrum results in reduced $\mathrm{ICl}$ when using OBPFs to extract the subcarriers as sketched in Fig. 1.

\section{Experimental setup and results}

The experimental set-up is shown in Fig. 2. The output of a $10 \mathrm{GHz}$ MLL at $1542 \mathrm{~nm}$ is spectrally broadened by self-phase modulation in a dispersion-flattened highly nonlinear fibre (DFHNLF). The broadened signal is DPSK modulated with a $10 \mathrm{Gbit} / \mathrm{s} 2^{15}-1$ PRBS. The resulting white spectrum is split in 4 paths connected to the four input ports of the WSS (Finisar Waveshaper 4000S). Dispersion-shifted fibers (DSF) of lengths 250, 500 and $1000 \mathrm{~m}$ are inserted to avoid coherence between the 4 input signals. Polarization controllers are used to align the polarization states for all 4 ports. With the WSS configured for spectrally resolved multiport splitting, each port generates seven $12.5 \mathrm{GHz}$ full-width at half maximum (FWHM) sinc subcarriers spaced by $50 \mathrm{GHz}$ with each port offset by $12.5 \mathrm{GHz}$. The resulting four signals are combined to create a $280 \mathrm{Gbit} / \mathrm{s}$ OFDM signal at the WSS output port. In the receiver, $4 x$ spectral magnification is achieved using two time-lenses where the quadratic phase modulation is achieved by FWM processes in
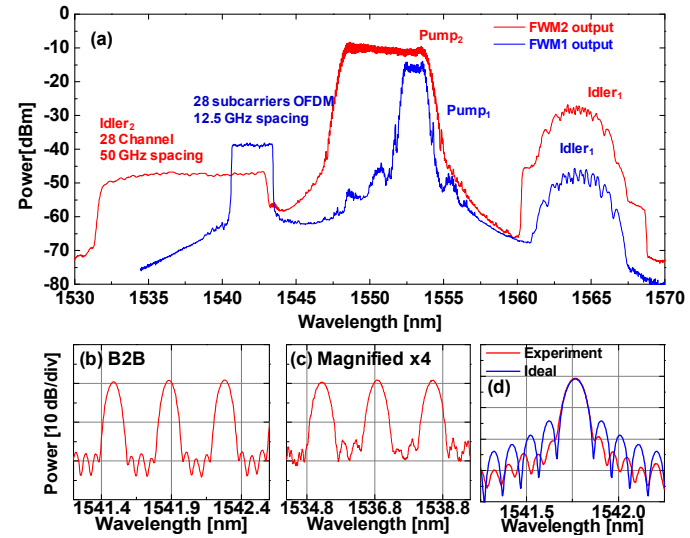

Fig. 3: (a) Optical spectra after the first (blue) and second (red) FWM process. (b) zoom-in of original OFDM from WSS Port 1 , and (c) after the $4 x$ magnification, (d) generated $12.5 \mathrm{GHz}$ sinc spectrum (red) and the ideal sinc (blue) plotted with $0.02 \mathrm{~nm}$ res.
$\mathrm{HNLF}_{1}$ and $\mathrm{HNLF}_{2}$ using linearly chirped rectangular pump pulses, pump $p_{1}$ and pump $_{2}$, respectively ${ }^{5}$. The pump pulses are from a $10 \mathrm{GHz}$ MLL at $1557 \mathrm{~nm}$ followed by spectral broadening in a DF-HNLF. Pump 1 (1553 nm) and pump $_{2}(1551 \mathrm{~nm})$ are obtained by parallel filtering and splitting in $\mathrm{WSS}_{2}$ followed by $3 \mathrm{~km}$ and $0.75 \mathrm{~km}$ SMF propagation, respectively.

The first FWM output spectrum is shown in Fig. 3 (a). The idler signal at $1564 \mathrm{~nm}$ is filtered out using an OBPF, and sent through $175 \mathrm{~m}$ dispersion-compensating fibre (DCF). This signal is combined with pump $\mathrm{p}_{2}$ and coupled into the $\mathrm{HNLF}_{2}$ for the second FWM process. The resulting spectrum is also shown in Fig. 3 (a). The generated idler is the output OFDM spectrum, magnified by a factor 4 compared to the input. Fig. 3 (b) and (c) show a zoom-in on the original OFDM subcarriers generated from WSS Port 1 and on its magnified spectrum, respectively. The 28 subcarriers are individually filtered out using an optical tunable filter (Santec OTF-350), with a Gaussian-like profile of $0.13 \mathrm{~nm}$ FWHM. The bit-error rate (BER) performance is measured in a $10 \mathrm{Gbit} / \mathrm{s}$ preamplified DPSK receiver with a $10 \mathrm{GHz}$ delay interferometer (DLI), balanced photo-detection (BPD) and 7.5 GHz electric low-pass filter. The resulting $10 \mathrm{Gbit} / \mathrm{s}$ DPSK BER curves are plotted in Fig. 4. After 4x spectral magnification, error free performance $\left(B E R<10^{-9}\right)$ is achieved for nearly all channels due to the reduced $\mathrm{ICI}$. In order to show the relative improvement from the magnification, the OTF (FWHM $0.08 \mathrm{~nm}$ ) is applied directly to the original OFDM signal to filter out the subcarriers (B2B). As shown in Fig. 4 (b), most of the subcarriers have a large error floor between $10^{-5}$ and $10^{-9}$ due to the large $\mathrm{ICl}$ (except the two edge channels where the $\mathrm{ICl}$ is lower). Note that the BER performance in this experiment is limited by the resolution of the WSS, which prevents the generation of an ideal 12.5 GHz sinc spectrum. As shown in Fig. 3 (d), the obtained sinc has slightly distorted sidelobes and uneven null-spacings, resulting in increased $\mathrm{ICl}$ for the magnified case and reduced $\mathrm{ICl}$ for the unmagnified case. We therefore supplement 

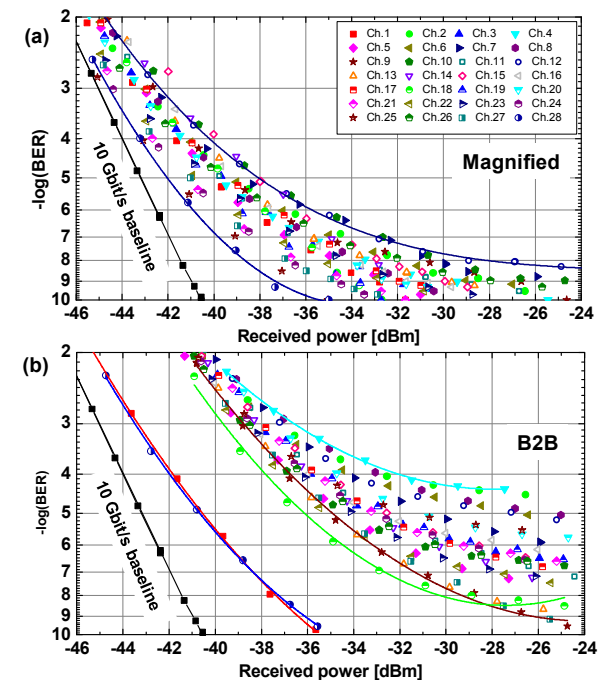

Fig. 4: BER performance (a) after $4 x$ spectral magnification. (b) B2B case (no magnification).

our experimental results with numerical simulations to investigate spectral magnification of ideally sinc-shaped subcarrier OFDM signals.

\section{Numerical simulations}

We performed Monte Carlo simulations on an OFDM signal consisting of eleven 10 Gbaud subcarriers at $12.5 \mathrm{GHz}$ spacing, each shaped as a $12.5 \mathrm{GHz}$ sinc (roll-off factor 0.1 ). The 11 optical carriers have zero linewidth and identical phases. Thus, the simulation cannot predict the exact BER for a system with incoherent carriers, but it can give indications of the relative improvement obtainable with magnification. The subcarriers are independently data-modulated with random and uniformly distributed bits using either DPSK or DQPSK. The spectral magnifier is implemented using ideal parabolic phase modulators. Magnification factors $M=1,2,4$ and 8 are tested. The OFDM signal is noiseloaded with ASE before the magnifier (out-ofband ASE is removed using a rectangular filter). After magnification, the central subcarrier (no. 6) is filtered out using a $2^{\text {nd }}$ order super-Gaussian (SG) OPBF with FWHM optimized depending on

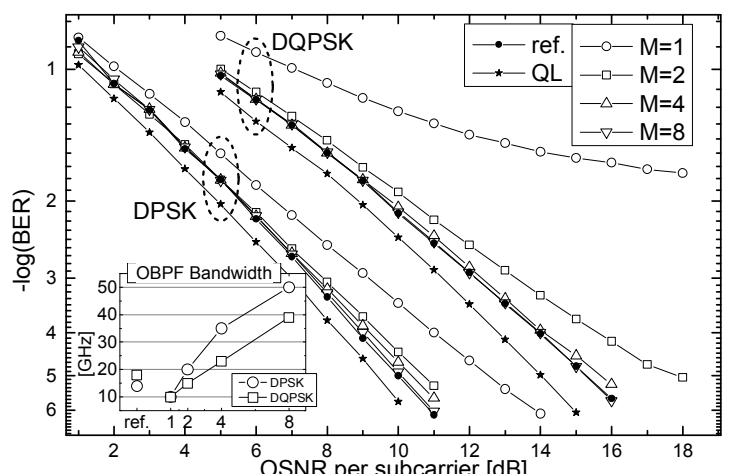

Fig. 5: Numerical simulations of the spectral magnification receiver performance, showing BER vs OSNR per 10 Gbaud subcarrier vs $M$ for DPSK and DQPSK (noise reference bandwidth is $12.5 \mathrm{GHz}$ ). The inset shows the OBPF bandwidth for the ref. and vs. M.
M. The filtered subcarrier is detected in an ASElimited receiver consisting of a $10 \mathrm{GHz} \mathrm{DLI}$, a BPD (no detector noise), and a $7.5 \mathrm{GHz} 4^{\text {th }}$ order Bessel filter. To estimate the BER, iterations of 1024 symbols are repeated until at least 100 errors are obtained. Each BER value is obtained by averaging over 5 simulations. The results are shown in Fig. 5 as BER vs OSNR per subcarrier. As a reference, we calculate the BER performance in the absence of the neighbor subcarriers and without magnification (ref). The quantum limit for the reference (matched optical filter and no electrical filtering) is also shown (QL). In general, the simulation results indicate an improved BER performance for increasing $M$. Furthermore, the improvement relative to filtering only $(M=1)$ is higher for DQPSK compared to DPSK. For DPSK, $M=1$ allows a $B E R<10^{-5}$, and $M=2$ is sufficient for an OSNR penalty less than $1 \mathrm{~dB}$ relative to the reference (down to $B E R \sim 10^{-6}$ ). For DQPSK, which is more sensitive to $\mathrm{ICl}, M=2$ results in much larger BER improvement, and $M=4$ is sufficient for a penalty less than $1 \mathrm{~dB}$.

\section{Conclusions}

We have demonstrated a 28 × $10 \mathrm{Gbit} / \mathrm{s}$ DPSK AO-OFDM system using a WSS-based transmitter and a receiver based on spectral magnification, enabling error-free performance for nearly all subcarriers after OBPF filtering. Furthermore, Monte Carlo simulations indicate that spectral magnification enables even larger BER improvements for DQPSK.

\section{Acknowledgment}

OFS Denmark Aps, Danish Research Council FTP project TOR (ref. no. 12-127224), Australian Research Council CUDOS (ref. no. CE110001018, FL130100041, LP0989752, FL120100029 and DE120101329).

\section{References}

[1] D. Hillerkuss et al., " 26 Tbit s $^{-1}$ line-rate super-channel transmission utilizing all-optical fast Fourier transform processing," Nat. Photon. 12, 364-371 (2011).

[2] J. Schröder et al., "All-Optical OFDM With Cyclic Prefix Insertion Using Flexible Wavelength Selective Switch Optical Processing," J. Lightwave Technol. 32(4), 752759, (2013).

[3] A. J. Lowery et al., "All-optical OFDM transmitter design using AWGRs and low-bandwidth modulators," Opt. Express 19(17), 15696-15704, 2011.

[4] P. Guan et al., "Real-Time All-Optical OFDM Transmission System Based on Time-Domain Optical Fourier Transformation," OFC'14, W4F.1 (2014).

[5] E. Palushani et al., "All-optical OFDM demultiplexing by spectral magnification and band-pass filtering," Opt. Express 22(1), 136-144 (2014). 
